\title{
Trabalho interprofissional na Estratégia Saúde da Família - relato de experiência de uma proposta de formação continuada de trabalhadores
}

Ana Paula Neri, Grace Jacqueline Aquiles, Adriana Sant'Ana Gasquez, Clicie Arrias Fabri, Heloisa Amboni de Oliveira

\begin{abstract}
Resumo
Com a implantação da Estratégia Saúde da Família (ESF), tem-se discutido sobre o desafio de formar profissionais para uma atuação de caráter interprofissional e valorização das práticas colaborativas, em uma visão usuário centrada. A formação de profissionais de saúde e o desenvolvimento dos trabalhadores que atuam no Sistema Único de Saúde (SUS) são eixos fundamentais da Política Nacional de Educação Permanente em Saúde e devem acontecer de forma indissociada e organizada a partir das necessidades de saúde da população e do território (BRASIL, 2016). Este relato tem como objetivo descrever a atuação da preceptoria para uma equipe da ESF de uma Unidade Básica de Saúde de um município de médio porte do noroeste do Paraná. Metodologia: Na organização do processo de trabalho da equipe da ESF, preconizou-se as reuniões semanais com os trabalhadores, para um trabalho de formação em relação a tomada de decisões e planejamento de suas ações. Percebia-se nessas ocasiões uma disputa entre as categorias profissionais na escolha dos problemas a serem abordados prioritariamente pela equipe. A preceptoria da equipe, fundamentada nos conceitos de interprofissionalidade e colaboração ativa e aliada às metodologias ativas de ensino aprendizagem, estruturou o espaço de debates e pactuação da equipe. Para auxiliá-los nas discussões e demandas cotidianas foi elaborado um instrumento, onde constam as solicitações individuais à equipe e suas contrareferências. Para as demandas de caráter mais abrangente utiliza-se um método de planejamento estratégico situacional. Resultados e Conclusão: Nesses encontros as metodologias ativas proporcionaram um deslocamento dos trabalhadores de um papel passivo de receber e reproduzir conceitos para atividades que produziram um pensamento ativo e contribuíram para parte de uma mudança no local de trabalho. Nessa perspectiva o trabalho interprofissional mediado pelas metodologias ativas, foram ponto de partida para reflexões e reelaboração de novas práticas de cuidados.
\end{abstract}

Descritores: Interprofissional, Planejamento estratégico, Metodologias ativas, Educação permanente praticas de cuidado 